\title{
Revalidating Sherlock Holmes for a role in medical education
}

\author{
David Levine
}

\begin{abstract}
Sir Arthur Conan Doyle endowed Sherlock Holmes with extraordinary skills that Dr Watson and others found incomprehensible until Holmes gave explanations, often in the form of memorable maxims and short monologues. Intentionally or not, Doyle left us crime-solving precepts that still inform aspects of medical practice. Experienced clinicians share with Holmes the dilemma of how to make complex, often unconscious, capability accessible to novices. Doctors still invoke Holmes's methods in clinical contexts, but the validity of some of the parallels has been challenged and quoting the more popular sayings has been equated with conceit. This paper examines how the use of selected maxims and monologues can help to link abstract principles and live context in a credible way in order to make aspects of clinical reasoning and professional behaviour more accessible and memorable.
\end{abstract}

KEY WORDS: diagnostic reasoning, Dr Watson, maxims, professional behaviour, Sherlock Holmes

\section{Introduction}

Sir Arthur Conan Doyle's fictional detective, Sherlock Holmes, is among the most quoted characters in English literature, and doctors still invoke Holmes's methods in clinical contexts. Many authors have argued over parallels between Doyle's stories and medical practice; in perhaps the best of these reviews, Reed rightly concludes that, although there are parallels, Holmesian deduction cannot be used as a direct paradigm to the process of diagnosis because solving medical problems operates on many other levels. ${ }^{1}$

Although I look at aspects of deduction in this paper, I want to concentrate more on the ways in which some, often lesser known, quotes might help to make specific clinical and professional precepts more accessible. The quotes are mixtures of short monologues and pithy sayings that I call maxims, because this and axioms are the terms most used in the stories. Aphorism is a virtually synonymous term. Although I refer to Holmes as our guide, this is always as a proxy for the skills of Doyle and Dr Joe Bell, who was Doyle's main inspiration for the methods, if not always the character, of his fictional hero. ${ }^{2}$

Two questions arise. First, why are the maxims and monologues still so often quoted? Second, how might we use them to help understand and teach clinical reasoning and professional behaviours?

David Levine, honorary fellow and retired consultant physician

Peninsula College of Medicine and Dentistry, Plymouth

\section{Why is Holmes still so quotable?}

Holmes's maxims and monologues have few of the poetic devices that make many medical aphorisms memorable and powerful, ${ }^{3}$ and yet they still hold our imagination. One reason may be that crime and illness present similarly as baffling problems that need explanation. Unlike much detective fiction, medicine often does not lend itself to clear solutions, but we are inclined to listen when a commanding voice seems to offer advice. The maxims have an aura of generalised authority that can invite quotation in many circumstances; this is a tribute to Doyle's skill in condensing wisdom, but it poses problems for validity. To offer maxims as guidance in medicine, we should first evaluate them in our specific work contexts.

Rapezzi and colleagues discuss similarities between reasoning in medicine and investigative methods of several fictional detectives. ${ }^{4}$ They propose that the genre provides clues on how to confront the problems of burgeoning technology and how to reconsider personal thought processes that are still essential in medicine. They conclude, in curiously Holmesian style, that 'Many of Holmes's best aphorisms provide a perfect fit with the medical world and hospital life and could be uttered by any physician [my italics] with an inflated ego similar to that displayed by Holmes'. I hope to show that fellows and members of the Royal College of Physicians might usefully quote without bearing the burden of arrogance.

I shall concentrate on two main areas: first, on skills of reasoning and diagnosis, which are difficult both to teach and to acquire, and second, on some unacknowledged parallels to educational and professional precepts that are often considered of more recent origin.

\section{Maxims and monologues for reasoning, observation and diagnosis}

One criticism has been that Holmes contradicts himself in how he claims to reason. Rapezzi et al suggested that Holmes does not generally apply hypothetico-deductive or inductive models of reasoning and suggested that he uses abduction. ${ }^{4}$ They paraphrase, and perhaps oversimplify, CS Peirce's description of abduction as 'nothing but guessing. Holmes rebuts that accusation:

I never guess. It is a shocking habit - destructive to the logical faculty.

(The sign of four)

Peirce gave a rather more qualified description and recognised intuition as part of abduction, which also encompasses close use of the senses in expertise, where noticing cues and clues seems to be 'intuitive' but is rather 'unconscious' or guided by tacit 
knowing. This is well documented as 'system'1, or 'non-analytic', diagnostic reasoning: ${ }^{5}$

It is the scientific use of the imagination, but we always have some material basis on which to start our speculation. (The hound of the Baskervilles)

Two examples do suggest that Holmes collects data without any guiding hypothesis:

I have not all my facts yet but I do not think there are any insuperable difficulties. Still, it is an error to argue in front of your data. You find yourself insensibly twisting them round to fit your theories. (The singular experience of $\mathrm{Mr}$ John Eccles)

Now, I make a point of never having any prejudices, and of following docilely wherever fact may lead me. (The adventure of the Reigate squire)

Generations of medical students interpreted their own teaching in this way: to take a history, examine the patient and then do some tests, 'docilely', before attempting a diagnosis. But experienced doctors formulate diagnostic hypotheses very quickly and then test these with questions, examination and investigations. ${ }^{6}$ Holmes is certainly not constrained by a single method, and in one tale we see that he did indeed use hypothetico-deductive method, albeit thinking this was wrong:

One forms provisional theories and waits for time or fuller knowledge to explode them. A bad habit, Mr Ferguson, but human nature is weak. I fear that your old friend here has given an exaggerated view of my scientific methods. (The adventure of the Sussex vampire)

The following monologue fits some descriptions of abduction and is relevant to diagnosis:

Let me see if I can make it clearer. Most people, if you describe a train of events to them, will tell you what the result would be. They can put those events together in their minds, and argue from them that something will come to pass. There are few people, however, who, if you told them a result, would be able to evolve from their own inner consciousness what the steps were which led up to that result. This power is what I mean when I talk of reasoning backward, or analytically. (A study in scarlet)

Anyone can look up what findings might be seen with a particular disease. The more valuable clinical skill is to consider what might have caused illness in a particular patient. Rather than trying to fit diagnosis and crime investigation into one common paradigm, we could review how clinicians reason and then consider whether we might make some abstract principles more understandable using familiar and memorable literary analogies. Holmes employs several reasoning strategies, as do we in medicine: initial reasoning using intuition or imagination becomes more likely with increasing experience of illness scripts, whereas a novice may use mainly an analytic approach. In practice, better results occur with a combination of methods: novices are advised not to neglect gut feelings and experts are encouraged to include more analytic reasoning in their approach. ${ }^{7}$ Armed with initial impressions, we then reason backwards.

Although it is an oversimplification to link crime solving and diagnosis in a single method, part of the value of modelling is its simplification of complex processes. The choice of methods or models varies according to context. The analogy is with maxims that often contradict each other, because they need to be applied case by case rather than universally. ${ }^{6}$

Some comments have other implications for clinical reasoning:

You did not know where to look, and so you missed all that was important. (A case of identity)

Looking with an open mind is important but unless we know what we are looking for, we often will not find it. We do not pretend that doctors could emulate Holmes in identifying many occupations from visual clues, but a good case has been made for enhancing diagnosis by careful observation of other 'extracorporeal' signs. ${ }^{8}$

Importantly, Holmes reminds us to avoid the cognitive error of premature diagnostic closure:

One should always look for a possible alternative, and provide against it. It is the first rule of criminal investigation. (The adventure of black Peter)

One monologue concisely explains the difference between populations and individuals, which is so important for many areas of clinical reasoning.

'Winwood Reade is good upon the subject', said Holmes. 'He remarks that, while the individual man is an insoluble puzzle, in the aggregate he becomes a mathematical certainty. You can, for example, never foretell what any one man will do, but you can say with precision what an average number will be up to. Individuals vary, but percentages remain constant. So says the statistician.' (The sign of four)

Gould ${ }^{9}$ restated this concept with characteristic clarity to illustrate the pitfalls of predicting survival.

Holmes understood the difficulty of articulating tacit, or expert, knowledge and technique:

It was easier to know it than to explain why I know it. If you were asked to prove that two and two made four, you might find some difficulty, and yet you are quite sure of the fact. (A study in scarlet)

Unfortunately, he sees it as threatening his status rather than helping others to learn:

... if I show you too much of my method of working, you will come to the conclusion that I am a very ordinary individual after all. (A study in scarlet)

Verbalisation is important in many areas of training, particularly for complex skills. The expert must move back from unconscious to conscious competence in order to explain how something is done rather than simply demonstrating impressive, but incomprehensible, skill to novices. ${ }^{10}$ We must encourage learners to articulate thought processes. ${ }^{11}$ The provenance of the 
conscious competence model is still debated, but it is usually thought to be recent. Lane refers to work by Posner that distinguishes conscious from automatic attention or processing. ${ }^{12}$ There are suggestions that William James mentioned similar ideas in the late nineteenth century; if true, it is possible that Doyle knew this. One other application is in case presentations, which are still so important for our learning:

Nothing clears up a case so much as stating it to another person. (The adventure of silver blaze)

\section{Maxims and monologues for professional behaviour}

The value of maxims goes beyond clinical reasoning to inform general professional behaviour. Many quotes depict Holmes as arrogant and insensitive, but a review in more depth might be useful when modelling doctors' professionalism. The next two maxims warn of common traps: the first needs no explanation; the second may be a memorable way to emphasise a dry rule about not denigrating other professionals. Recognising the unattractiveness of an inflated ego might even help to avoid copying it:

A client is to me a mere unit, a factor in a problem.(The sign of four)

Lecoq was a miserable bungler... The question was how to identify an unknown prisoner. I could have done it in twenty-four hours. Lecoq took six months or so. It might be made a textbook for detectives to teach them what to avoid. (A study in scarlet)

We must remember that, in addition to having doctors for model and creator, the detective has most of his exploits related to us by Dr Watson. Although often dismissed as a dullard, Watson is crucially important in several ways: his role and style are particular reasons that we find Holmes memorable. No one explains this better than Le Carré in his masterful introduction to Klinger's annotated edition of the canon. ${ }^{13}$ Looking at how Holmes treats his loyal friend, we see ways in which eminence might slip into arrogance:

Should you care to add the case to your annals, my dear Watson, it can only be as an example of that temporary eclipse to which even the best-balanced mind may be exposed. Such slips are common to all mortals, and the greatest is he who can recognize and repair them. (The disappearance of Lady Frances Carfax)

'Really, Watson, you excel yourself', said Holmes... 'I am bound to say that in all the accounts which you have been so good as to give of my own small achievements you have habitually underrated your own abilities. It may be that you are not yourself luminous, but you are a conductor of light. Some people without possessing genius have a remarkable power of stimulating it. I confess, my dear fellow, that I am very much in your debt.'(The hound of the Baskervilles)

Watson does not seem to understand sarcasm:

...I must admit that his words gave me keen pleasure, for I had often been piqued by his indifference to my admiration...

Holmes adds:
When I said that you stimulated me I meant, to be frank, that in noting your fallacies I was occasionally guided towards the truth.

But, two admissions from Holmes remind even the most eminent of their indebtedness to unsung helpers and of the need to recognise and admit error:

I am lost without my Boswell (A scandal in Bohemia)

Watson, if it should ever strike you that I am getting a little overconfident in my powers, or giving less pains to a case than it deserves, kindly whisper 'Norbury' in my ear, and I shall be infinitely obliged to you. (The adventure of the yellow face)

In 1917, Doyle gave us a memorable exchange after the two have captured a spy and are reflecting by the sea for a few moments:

'There's an east wind coming, Watson.'

'I think not, Holmes. It is very warm.'

'Good old Watson! You are the one fixed point in a changing age...' (His last bow)

No longer patronising, this simply demonstrates the esteem in which he holds his friend and the recognition that they work as a team. Watson is a stranger to metaphor, but he is not ridiculed for this - just valued for what he is. We might note that Doyle wrote this shortly before his son, Langley, died of pneumonia, having sustained wounds on the Somme the previous year. Perhaps, anticipating this, Doyle then endowed Holmes with more humanity.

Advice on a core aspect of professionalism is still fresh:

It is of the first importance not to allow your judgment to be biased

by personal qualities. (The sign of four)

Lastly, a Victorian warning, so recently reincarnated:

... When a doctor does go wrong he is the first of criminals. He has nerve and he has knowledge. (The adventure of the speckled band)

\section{Discussion}

When teaching, we need to be aware of differences between experts and novices. ${ }^{14}$ These differences involve ways of seeing and reasoning even more so than formal knowledge. They are often ignored but may be so profound that they impair both the ability of experts to explain skills to novices and of novices to understand what experts are saying or doing. In addition to other techniques, using references to famous literary characters and stories can help make some explanations more accessible to novices.

Why else might maxims even be necessary in medicine? Most information is easily available almost anywhere online, but there is a big gap between information and knowledge about patients. Innumerable, often lengthy, guidelines and protocols tend to be filed and forgotten. Few of them are written in ways that allow them to be helpful in making judgements and choices 'on the spot. ${ }^{15}$ To function under pressure, we use cognitive shortcuts, rules of thumb or heuristics. ${ }^{16}$ Maxims and similar devices are 
easily recalled and powerful forms of heuristics - here seen through the lens of iconic fictional characters. Instead of using maxims purely for certainty and finality, we can also use them to discuss uncertainty, contradiction and ambiguity, as these are the realities of medicine.

One problem with memorable quotes is that they become clichés - useful only for dramatic effect if offered out of context or without discussion. They can also simply become mantras for experts, who, over years, invest them with personal meanings that may not be apparent to novices. When offered as authoritative statements of how (or how not) to think or behave, they may invite use in a generalised way rather than in specific contexts. To avoid these pitfalls, they might be offered to learners not as definitive pearls of wisdom but for discussion as bridges between the abstract principle and the live context. ${ }^{3,17}$

Rapezzi and colleagues warn of the risk of a '...new prototype doctor... an armchair specialist armed with a high speed laptop and the conviction that the solution to every clinical dilemma is to be found on the web. ${ }^{4}$ McCrory reiterated this warning and suggested that Holmes's expertise in reasoning and his skill in taking a history are still relevant for doctors today. ${ }^{18}$ We need make no excuse for reading the stories simply for enjoyment, but although Doyle, modestly, said he wrote about crime only to help earn a living and denied parallels with medicine, he believed strongly in a morality of medicine and advocated literary sensibility for doctors to appreciate this. ${ }^{19}$ I like to believe that he embedded medical allegories and metaphors for those who might find them useful, particularly as these factors are so important for attributing meaning to patients' stories. ${ }^{20} \mathrm{I}$ hope I have illustrated the continuing power of Holmes's maxims. His monologues still inspire ways to enhance our reasoning and professional awareness, and they reassure us that it is possible for physicians to quote them while retaining a modicum of humility.

\section{Acknowledgements}

To the memory of my clinical teachers and mentors. My thanks also to Dr Jill Schostak and Professor Alan Bleakley for their valuable comments on this paper.

\section{References}

1 Reed J. A medical perspective on the adventures of Sherlock Holmes. Med Humanit 2001;27:76-8.

2 Liebow E. Dr Joe Bell: model for Sherlock Holmes. Bowling Green: Popular Press, 2007.

3 Levine DF, Bleakley A. Maximising medicine through aphorisms. Med Educ 2012;46:153-62.

4 Rapezzi C, Ferrari R, Branzi A. White coats and fingerprints: diagnostic reasoning in medicine and investigative methods of fictional detectives. BMJ 2005;331:1491-4.

5 Eva K. What every teacher needs to know about clinical reasoning. Med Educ 2004;39: 98-106.

6 Montgomery K. How doctors think. Clinical judgement and the practice of medicine. Oxford: Oxford University Press, 2006

7 Croskerry P. A universal model of diagnostic reasoning. Acad Med 2009;84:1022-8.

8 Fitzgerald FT, Tierney LM. The bedside Sherlock Holmes. West J Med 1982;137:169-75.

9 Gould SJ. The median isn't the message. Discover 1985;6:40-2.

10 Peyton JWR. Teaching and learning in medical practice. Rickmansworth: Manticore Europe, 1998.

11 Neher JO, Gordon KC, Meyer B, Stevens N. A five-step 'microskills' model of clinical teaching. J Am Board Fam Pract 1992;5:419-24.

12 Lane DM. Limited capacity, attention, allocation and productivity. In: Howell C, Fleishman EA, eds. Human productivity and performance. Volume 2: information processing and decision making. Hillsdale, New Jersey: Lawrence Erlbaum Associates, 1982.

13 Doyle AC, Klinger LS, ed. The new annotated Sherlock Holmes. New York: WW Norton and Company, 2005.

14 Andre D, Fernand G. Sherlock Holmes - an expert's view of expertise. Br J Psychol 2008;99:109-25.

15 Brush JE Jr, Radford MJ, Krumholz HM. Integrating clinical practice guidelines into the routine of everyday practice. Crit Pathw Cardiol 2005;4:161-7.

16 Wegwarth O, Gaissmaier W, Grigerenzer G. Smart strategies for doctors and doctors-in-training. Med Educ 2009;43:721-8.

17 Dudley HAF. Axioms in clinical practice and their potential use in education. Med Educ 1982;16:308-13.

18 McCrory P. Elementary, my dear Watson. Br J Sports Med 2006;40:283-4.

19 Doyle AC. The romance of medicine. Lancet 1910;2:1066-8.

20 Holmes J. Narrative in psychiatry and psychotherapy: the evidence? Med Humanit 2000;26:92-6.

Address for correspondence: Dr David Levine, The Craige, Sunny Corner Lane, Sennen, Cornwall TR19 7AX.

Email: david.levine@pms.ac.uk 